\title{
Marital life, sexual relations, and fertility health in Iranian HIV/AIDS patients: a qualitative study
}

\author{
Mmehrnoosh Khoshtarash $^{1}$, Mansoureh Ashghali Farahani ${ }^{1}$, Armin Zareiyan ${ }^{2}$ \\ ${ }^{1}$ Nursing Care Research Center (NCRC), School of Nursing and Midwifery, Iran University of Medical Sciences, Tehran, Iran \\ ${ }^{2}$ Public Health Nursing Department, Nursing Faculty, AJA University of Medical Sciences, Tehran, Iran
}

\begin{abstract}
Introduction: Although the rights, needs, and interests of reproductive and sexual health in human immunodeficiency virus (HIV)-positive women and men are similar to those of HIV-negative people, some biological and social differences require them to be given special attention. The aim of this qualitative study was exploring the sexual behaviours and reproductive health of people with HIV/acquired immunodeficiency syndrome (AIDS).

Material and methods: The data collected in this study included semi-structured, face-to-face and audio recorded interviews with 14 HIV/AIDS patients referring to the Behavioural Disease Counselling Centres of Tehran and Rasht (Iran). Purposeful sampling with maximum variation was used to select participants. The duration of the interviews was between 40 and 75 minutes. MAXQDA10 software was used to organise and manage the data, and conventional concept analysis was used to examine the data.

Results: Fifty-seven per cent of the participants were male and $64 \%$ were married. More than $90 \%$ of the participants had not had children since the disease. In the analysis of interviews, the following three themes were extracted: stressful marriage, sexual activity, and childbearing.

Conclusions: The findings of the study, not only in the field of health care management but also at the social level, have applications supporting people living with HIV/AIDS as well as non-affected people.
\end{abstract}

HIV AIDS Rev 2019; 18, 3: 207-214 DOI: https://doi.org/10.5114/hivar.2019.88357

Key words: fertility health, sexual relations, HIV, AIDS.

\section{Introduction}

Antiretroviral drugs around the world has reduced mortality, morbidity, as well as new cases of human immunodeficiency virus (HIV) infection, and has led to an increase in the quality of life of HIV-positive people [1,2]. Access to antiretroviral drugs increases the efforts to have a normal life and have sexual relationships and fertility in-

Address for correspondence: Dr. Mmehrnoosh Khoshtarash, Nursing Care Research Center (NCRC), School of Nursing and Midwifery, Iran University of Medical Sciences, Tehran, Iran, Rashid Yasemi St, Valiasr Ave, Tehran, Iran, e-mail: mehrnoosh_kh72@yahoo.com

tentions in the future [3]. Of the 37 million people infected with HIV in 2017, 35 million of them are adult men and women [4]. Most HIV-positive women are at the age of fertility [5], and every week about 7000 women aged 15 to 24 are infected with the virus [4]. Thus, fertility issues for people living with HIV/acquired immunodeficiency syndrome (AIDS) (PLWHA) are becoming increasingly important [6].

Article history:

Received: 05.04.2019

Received in revised form: 15.04.2019

Accepted: 23.04.2019

Available online: 06.09.2019
International Journal of HIV-Related Problems

HIV \& AIDS

R e v i e w 
HIV-positive people have rights regarding fertility, sexual satisfaction, and safe sexual relations [7]. Achieving fertility rights for HIV-positive people is influenced by economic, social, and cultural factors, access to health care services, and the national and international laws and policies on providing appropriate reproductive health services and programs [8]. Obviously, the lack of access to reproductive health services will lead to increased vertical transmission (mother-to-child), transmission of infection to a partner, recurrence of infection and other infections, unwanted pregnancy, and unsafe abortion [9].

Although the rights, needs, and interests of reproductive and sexual health in HIV-positive women and men are similar to those of the HIV-negative population, some biological and social differences between HIV-positive and HIVnegative people require the former group to be given special attention [10]. HIV/AIDS can directly lead to increased spontaneous abortions or indirectly reduce sexual desire, cause marital problems, and compulsory use of condoms [5]. Also, unlike the general population, HIV-positive people are struggling with the problems of balancing fertility intentions with the need to protect themselves and their sexual partner against re-infection and the birth of a non-HIV child [11]. In addition, an important aspect of the lives of PLWHA is sexual relations, like other people. Although many of them may decide to stop their sexual activity, sexual life will not be stopped by the diagnosis of HIV [9, 12-17]. A study in developed countries has shown that more than $70 \%$ of HIV-positive people remain sexually active [18].

On the other hand, improving the health status of patients with antiretroviral drugs, along with the belief in patients that the disease can be treated with these drugs, can lead to high-risk sexual behaviours [19], which has consequences such as horizontal transmission to a partner, recurrent infections with multiple chains of HIV or other sexually transmitted diseases, and drug resistance [20,21].

Unfortunately, the issues focused on sexual and reproductive health services for HIV-positive people focus more on controlling fertility and preventing the vertical and horizontal transmission of disease, and other needs of these people, including respect for healthy and safe sex and the desire to have a baby, are ignored. Therefore, this study was conducted to explore the sexual behaviours and reproductive health of people with HIV/AIDS.

\section{Material and methods}

The data were collected from 14 people living with HIV/ AIDS (PLWHA) referring to the Behavioural Disease Counselling Centres of Imam Khomeini Hospital (Tehran) and Rasht, from April to September 2018. Purposeful sampling was used to select participants, and maximum variation in the selection of participants was observed. The inclusion criteria included speaking in Persian and a willingness to participate in the study. Semi-structured, face-to-face and audio recorded interviews were used to collect data. The research team developed an open-ended interview guide with the following questions: Can you explain your marital experiences? Can you explain your sexual activity? Can you express your own thoughts and experiences about having children? Comments and questions were followed up with prompts such as 'tell me more about this'. When new data were not received, the interviews ended. The interviews were conducted by the corresponding author in a private room (Mostly at Imam and Rasht Hospital Consulting Centre), and the duration of the interviews was between 40 and 75 minutes (average 45 minutes). All 14 interviews were transcribed and then MAXQDA10 software was used to manage and organise the data. For data analysis, a conventional content analysis method was used based on the proposed model of Graneheim and Lundman [22]. First, the interviews were read word by word, line by line, and paragraph by paragraph several times in order to obtain the general understanding. Then, the meaning units and initial codes were extracted. The codes were categorised by performing continuous comparisons in different categories and subcategories according to their repetition, differences, and similarities.

In qualitative research many factors need to be taken into account to ensure trustworthiness. To ensure the rigor of data, the Lincoln and Guba criteria were used [23]. Member check, Peer check and External check, sampling with maximum variation, prolonged engagement during the data collection and analysis, recording participants' statements, and writing all the research steps accurately were among the most important strategies used to ensure the trustworthiness of the data.

\section{Ethical consideration}

The study was approved by the Ethics Committee of Iran University of Medical Sciences (Ethics approval number IR.IUMS.FMD.REC.1395.9221199206). All participants provided prior written informed consent and were informed that they could withdraw at any time without negative consequence. They were assured that interviews would be completely confidential and results would be reported anonymously.

\section{Results}

Fifty-seven per cent of the participants were male and $64 \%$ were married. More than $90 \%$ of the participants had not had children since the disease. The general information about the participants is presented in Table 1. In the analysis of interviews, the following three themes were extracted: 1) stressful marriage, 2) sexual activity, and 3) childbearing (Table 2).

\section{Stressful marriage}

Challenges related to marriage were one of the important issues that participants, especially single PLWHA, referred to, including two subcategories of unstable marriage and marital rearrangement. 
Table 1. Demographic characteristics of the participants

\begin{tabular}{|c|c|}
\hline Variable & Frequencies \\
\hline \multicolumn{2}{|l|}{ Gender } \\
\hline Male & 8 \\
\hline Female & 6 \\
\hline Age & $25-48$ y \\
\hline \multicolumn{2}{|l|}{ Marital status } \\
\hline Married & 9 \\
\hline Single & 5 \\
\hline \multicolumn{2}{|l|}{ Education } \\
\hline Middle school & 2 \\
\hline Diploma & 10 \\
\hline Bachelor & 2 \\
\hline \multicolumn{2}{|l|}{ Occupational status } \\
\hline Unemployment & 4 \\
\hline Self-employment & 1 \\
\hline Worker & 2 \\
\hline Housewife & 5 \\
\hline Employed & 2 \\
\hline \multicolumn{2}{|l|}{ Transmission } \\
\hline Jointly used needle & 3 \\
\hline Extramarital sex & 4 \\
\hline Infected husband & 2 \\
\hline Tattoos & 2 \\
\hline Probably dentistry & 1 \\
\hline Unknown & 2 \\
\hline \multicolumn{2}{|l|}{ Time of diagnosis (years) } \\
\hline 1 & 1 \\
\hline $1-5$ & 7 \\
\hline $6-10$ & 3 \\
\hline \multicolumn{2}{|l|}{ Number of children } \\
\hline No children & 7 \\
\hline 1 child & 6 \\
\hline 2 children & 1 \\
\hline \multicolumn{2}{|l|}{ Partner's serostatus } \\
\hline Negative & 12 \\
\hline Positive & 2 \\
\hline \multicolumn{2}{|l|}{ Having multiple partners } \\
\hline Yes & 2 \\
\hline No & 12 \\
\hline \multicolumn{2}{|l|}{ HIV disclosure to partner } \\
\hline Yes & 3 \\
\hline No & 11 \\
\hline \multicolumn{2}{|l|}{ Condom use } \\
\hline Yes & 12 \\
\hline No & 2 \\
\hline
\end{tabular}

Table 1. Cont.

\begin{tabular}{|c|c|}
\hline Variable & Frequencies \\
\hline \multicolumn{2}{|c|}{ Contraception use } \\
\hline Yes & 1 (emergency pills) \\
\hline No & 13 \\
\hline \multicolumn{2}{|c|}{ Intention to become pregnant } \\
\hline Yes & 1 \\
\hline No & 13 \\
\hline
\end{tabular}

Table 2. Categories and sub-categories of study

\begin{tabular}{l|c}
\hline Category & Subcategory \\
\hline \multirow{2}{*}{ Stressful marriage } & Unstable marriage \\
\cline { 2 - 2 } & Marriage rearrangement \\
\hline \multirow{2}{*}{ Sexual activity } & Sexual dissatisfaction \\
\cline { 2 - 2 } & Risky sexual behaviours \\
\hline \multirow{3}{*}{ Childbearing } & Fears, desires, and intentions \\
\cline { 2 - 2 } & Unintended vs. intended pregnancies \\
\cline { 2 - 2 } & Facing the event \\
\hline
\end{tabular}

\section{Unstable marriage}

For the majority of single people with HIV/AIDS, fear of disclosing illness and disloyalty, social stigma, and finding a person suited to the conditions of the disease for marriage were their main concerns about marriage. In this regard, one of the participants said: "I decided but I couldn't, because it is the first thing I should say to my partner. Others may ascertain and it may ruin my reputation" (P11). Another participant stated: "Well, we are different from others. I cannot marry. One of my anxieties is I couldn't find my partner who has the same status like me... but now I give it up because I couldn't find the desired case" (P8).

Some married people also mentioned the experience of divorce due to marital problems and distrust of their spouse and family and the resulting problems: "When my ex-wife found out my disease, she just lived with me for a short time... then she left me alone. She thought that before our marriage I knew about my sickness but I didn't tell her. It made me to be deeply on my own, loneliness, seclusion, isolation... and again drug abusing" (P6).

\section{Marriage rearrangement}

Despite all the concerns and problems, many PLWHA did not lose their hope and married with HIV-positive and even HIV-negative persons and said that their wife's support is crucial for their adaptation to the disease. In this regard, a 40-year-old woman said: "When I came here (the counselling centre) I met one of the patients who was sick like me. Now we have been married for two years. He understands me and he's trying to help me to cope with my illness" (P4). 


\section{Sexual activity}

Disturbances in the quantity and quality of sexual relations and high-risk sexual behaviours are two important subcategories of this theme.

\section{Sexual dissatisfaction}

The majority of participants in this study expressed a decline in sexuality and reduced satisfaction with their sexual relations. The fear of disclosure of disease and fear of their sexual partner's reaction were among the things that the participants referred to in this regard: "My sexual relationship declined. I don't have that former motivation at all, because I cannot talk about my problem... then when you want to use condom your partner will say that you're sick" (P11, Mr. Single 25 years old).

Some participants also expressed the fear of transmitting the disease to a partner as a major factor in reducing sexual relations and satisfaction: "Actually my sexual relationship has declined. Specially, at first I wonder what will happen if the condom will be torn up because he possibly become sick. By the way, it happened and we were very nervous to see the result of the test, but fortunately it was negative" (P13, Ms. 32 years old and married). Mr. 48 years old and single, said: "My sexual relationship has been limited. This illness makes you uncomfortable. Even if you have a protected sex, you cannot have a good sex and also you're under stress" (P8).

Discomfort during sex with a condom and coercive condom use was another issue that almost all of the participants mentioned, and in their view it influenced the quantity and quality of sex. In this regard, a 35-year-old married woman stated: "Our sexual relationship has been much less. I never take the initiative in sex. I always hate condom. I was always feeling something like my body smells like plastic. I'm not OK with condom, so I have to tolerate it" (P15). Another participant said: "I don't tend to have sex. The biggest thing that worries me is sex. It's intolerable to use condom for your whole life because I hate condom" (P9, Mr. Single 33 years old).

Mistrust of the sexual partner was another factor affecting sexual relations. In this regard, a 39-year-old single homosexual said: "From the day I found out I'm sick, my sexual relationship has been changed. That friendly relationship and reliance never came back. I couldn't find that previous comfort and reliable relationship" (P7).

\section{High-risk sexual behaviours}

Despite the fact that all participants stated that they had studied or been trained on safe sex, some of them continued to have high risk behaviours. The most important high-risk sexual behaviours of the participants were: multiple partners, having sex with sex workers, avoiding condom use, unprotected anal sex, and non-disclosure of disease to a partner. Mr. Single 33 years old said: "I've been with a girl about four years. She doesn't know I'm sick. I used condom for several times she didn't like it, then I didn't use it anymore. I'm not that brave enough to talk about my illness. Maybe she's sick now" (P9). Another participant stated: "I'm in a relationship and that person has HIV too. There were two or three people who had sex with me but I was extremely careful about it, but I didn't tell them about my illness. Also, I had anal sex, but the person had HIV too" (P8).

\section{Childbearing}

Most married participants, especially those who did not have a baby, and even some single persons, mentioned one of their main concerns as having a child. This theme includes three subcategories of: 1) fears, desires and intentions; 2) unintended vs. intended pregnancies; and 3) facing the event.

\section{Fears, desires, and intentions}

Although most participants were interested in having a child, they mentioned the uncertain future of the disease, the fear of transmitting HIV to the child or spouse, their wife's disagreement, poor physical condition or co-existing infections, and poor financial status among the main reasons for not having children. In this regard, one of the participants said: "I'd like to have baby, but I have hepatitis C. Then we have to spend a lot of money, so what's the benefit, then how long we want to live. So, who wants to grow up and look after my kid?" (Ms. 40 years old, without a child and with an HIV-positive spouse). A 35-year-old with one healthy child stated: "I'm afraid of having a baby because it's risky. My husband likes to have a kid, but I say "No", since probably my kid will get sick. Because of this I don't like to have a baby" (P2).

Despite all these fears and worries, some of them expressed their hope for having a child and included it in their future plans: "I like to have baby, but my doctor said that my CD4 should reach to its normal level, so now we're waiting for that and after that we'll proceed" (P13, Ms. 32-year-old with a healthy child and an HIV-negative husband).

\section{Unintended vs, intended pregnancies}

All of the participants only used condoms for contraception and did not use any of the hormonal and permanent methods. Women stated that if necessary, they would use emergency methods advised by health care providers at the counselling centre: "They gave me an emergency pill to use if it was needed" (P15). It is noteworthy that two women said that they had had unwanted or unplanned pregnancies since the time of the use of the condom.

\section{Facing the event}

Participants' experiences of intended pregnancies and how to deal with unwanted or unintended pregnancies are the main focus of this subcategory. One of the participants who had a child after HIV diagnosis and with full follow-up, said: "Well I came here (the counselling centre) 
I talked about my problem, then they helped me. I had no idea of having a baby so I didn't know what would happen. Through the experimental test my wife found out she was pregnant. I was really scared, and we decided to have a blood test. Even after that I called and got help from some centres in Tehran to be sure of anything" (P6). The fear of transmitting HIV to the child is such that some patients, regardless of the recommendations of health care services, end up becoming pregnant: (P15, Ms. 35-year-old with a healthy child and an HIV-negative husband) "When I was pregnant my test showed that I have HIV. So I came here (the counselling centre). They told me that I can keep my baby, but I didn't like to because I didn't want my baby to get HIV and I was afraid of being dead and my kid has to grow up without mother. Therefore, I went to forensic medicine to get a legal letter for curettage". Another participant said: "Last year I got pregnant haphazardly then we saw a doctor. He helped us about what things we have to do in order to have a healthy baby, but my husband disagreed then he thought it's impossible to have a healthy baby. He got a legal letter for curettage. I still love to have a baby, but my husband doesn't accept it" (P14, Ms. 32 years old, without a child and with an HIV-negative spouse).

\section{Discussion}

In this study, three themes were extracted from the interviews: stressful marital life, sexual activity, and childbearing.

Marriage is a serious component of the formation of any healthy society. The importance and necessity of family and marriage is not overlooked by anyone, which matters more in terms of the cultural and social requirements of our society [24]. Limitations on family formation and preservation are one of the social consequences of HIV/AIDS, which is the main source of concern for the majority of patients in this study. According to many participants, fear of disclosure of illness and disrepute and stigma in the community are among the most serious barriers to their marriage. Because, in society's perception, transmission of AIDS is related to infidelity and sexual activity, the majority of societies consider HIV patients to be disloyal, norm-breaking, and promiscuous people who deserve to be punished. On the other hand, incorrect beliefs in society based on AIDS transmission through physical proximity and direct interaction with the patient are kinds of AIDS phobia - an irrational and disproportionate fear that does not conform to objective and medical facts, which leads to the increased isolation of patients and the deprivation of their human rights, including family formation [25]. In Fallahi's study (2012), many patients also described marriage as a major challenge [26]. Participants in the study of Abachi and Beharvan (2012) also stated that they had encountered difficulties in their marital life and had experienced in some cases the separation from their spouse [27].

Despite the fact that all our study patients, both married and single, were sexually active, most of them were not satisfied with the quality and quantity of their sexual relations; they stated fear of disclosure of illness, fear of partner's reaction and rejection, not being comfortable with condom use especially permanent use, the fear of transmitting disease to the partner, and mistrust of the partner as the main factors. Although various studies on the prevalence of sexual activity in HIV/AIDS patients have reported $42-83 \%$ over the past 3,6 , or 12 months $[12-17,28,29]$, they have been less concerned with sexual satisfaction. In the Rispel study (2011), conducted in discordant couples, a large number of them expressed the fear of transmission of infection to their partner and thus reduced sexual intimacy [28].

High-risk sexual behaviours are a major risk factor for the transmission of disease, causing an increase in the incidence of disease and exacerbation of the HIV epidemic [30], and changing sexual behaviour is the most effective way of preventing HIV transmission [31]. People adopting risky sexual behaviours not only cause the spread of disease, but also infect themselves with multiple chains of HIV virus, other sexually transmitted disease, and drug resistance [9, 20, 21]. As with Gaed, 20\% of women have experienced at least one episode of an STD since HIV diagnosis [15].

One of the high-risk sexual behaviours in our study participants was having multiple partners and sex with prostitutes. Various studies have been done in this regard, For example, in the Amoran study, more than $47 \%$ of men and $52 \%$ of women over the past six months, and in the Johnson study $30 \%$ and $10 \%$ of men and women, respectively, had two or more sex partners $[30,32]$. Also, $21 \%$ of sexually active women in the Gaede study (2006) had two partners. Thirtyfive per cent of participants of the Bateganya study had one or two causal partners in addition to their main partner [17]. Sixteen per cent of participants in the Nedjat study had sexual relations with a regular partner other than their spouse, and $21 \%$ had causal partners [12]. Only in the study by Dessie did all of the patients claim that in the last three months they had had only one partner [33].

One of the other high-risk sexual behaviours of participants was the non-disclosure of the disease to their partner. In the studies of Adeniyi and King more than 25\% and 30\% of individuals, respectively, did not disclose their illness to their sexual partner $[14,34]$. Non-disclosure of the disease in the participants was mainly reported in relation to multiple or causal partners (non-marriage relationship). This finding was consistent with the results of studies by Esmaelzadeh-Saeieh, Cooper, and Kalichman [16, 35, 36]. Disclosing the disease to the partner is the responsibility of every sexually active PLWHA, which plays an important role in reducing risky behaviours and, consequently, preventing the spread of disease [35]. In the study of Crepaz and Marks, those who reported their illness to their sexual partner were significantly more likely to have protected vaginal or anal sex [37].

Another risky behaviour was the non-use or non-continuous use of condoms in sexual relationships $[12,13,16,17,29$, $32,33,38-40]$. Various statistics have been presented in studies in this area. For example, in a study by Dessie and Deresa, $23 \%$ of people did not use condoms at all [33], while the use of condoms was $80 \%$ in the study by Kalichman et al. [16]. 
Continuous condom use was reported in the Dessie study as $61.5 \%$, while in the Gogna study it was only $14.4 \%$ [33, 38]. The non-use or non-continuous use of condom in this study was reported primarily in men, as well as in sexual relations with partners other than their spouse, while individuals with an HIV-negative partner used condoms more often. In the Hajizadeh study in Iran, about 50\% of men had sex with HIV-negative partner without using a condom (compared with $15.6 \%$ of women) [29]. The level of non-use of a condom with a spouse was $57 \%$ and with a regular, causal, and commercial partner was $65 \%, 85 \%$, and $85 \%$ in the Bateganya study, respectively [17]. Our participants cited the decline in sexual pleasure, the fear of disclosure of illness to their partner, and unwillingness of their partner as the main reasons for non-use or non-continuous use of a condom, which was in line with the results of other studies [12, 28, 35, 40,41].

Another of the high-risk sexual behaviours of the participants was unprotected anal sex, which two male participants referred to. Johnson, Cunha, and Halkitis reported this risky behaviour as being more than $40 \%$ [30, 42, 43]. The point to consider was that all high-risk sexual behaviours were reported in single individuals. In the study by Debeko, single individuals more than others had high-risk sexual behaviours [8].

Planned pregnancy programs are essential for people with HIV/AIDS to reduce maternal and foetal complications and reduce the vertical and horizontal transmission of the disease [44]. Unfortunately, despite the clear link between family planning and AIDS, these two rarely combine [45], and many pregnancies are still unplanned $[12,36,38,44,46]$. Our study, in which two of the participants had an unplanned pregnancy experience while using condoms, also confirms this; both of them terminated the pregnancy. In the study of Nedjat and Smits, $32 \%$ and $3.6 \%$ of the individuals ended their pregnancy, respectively $[12,47]$.

Another topic extracted from interviews is the desires, intentions, and fertility experiences of the participants. Previous studies on fertility demands have shown that, like ordinary people, PLWHA have children [6, 12, 39, 48-51]; however, the fertility rate has fallen under the influence of various factors $[5,52,53]$. Most of our study participants also liked to own a child, but fear of the uncertain outcome of illness and orphanage, fear of HIV transmission to the child and wife, the wife's opposition, and inappropriate physical and economic conditions are among the main obstacles to decision making. This finding was in line with the results of other studies $[6,8,12,28,36,54-56]$. Only one participant had had a child after illness, and one person would like to have a child in the future. In various studies, between $28 \%$ and $55 \%$ of PLWHA experienced pregnancy after diagnosis [38, 44, 46, 48].

A remarkable positive point in the participants' talk was that before decision making to having children, during the pregnancy, and even for the termination of pregnancy in unwanted pregnancies, they referred to a specialist or Behavioural Disease Counselling Centres and refused to go to non-professional or illegal centres, which can be a sign of patients' trust in these centres and of a good relationship with health care providers. In a study by Loutfy, 51\% of women talked about pregnancy planning with health care providers, and in the Nedjat study, more than $65 \%$ of those who became pregnant after diagnosis had received prenatal care $[12,57]$. However, in a number of studies, people who had an interest in or intention of having children had difficulty talking to health care providers, and in some cases they were blamed or disappointed $[9,12,38,58]$.

\section{Conclusions}

The findings of the study, not only in the field of health care management but also at the social level, have applications that support PLWHA as well as non-affected people. Reporting of high-risk sexual behaviours by single people along with marital challenges poses the need for more attention to be paid to marriage, because by the reducing high-risk behaviours the spread of disease can be reduced. The unwillingness of the study population to have a baby along with evidence of reduced fertility rates in PLWHA in various studies on the one hand and the high prevalence of unplanned pregnancies in this population on the other hand highlights the need for more attention to the fertility health among these people. Policy makers and health care providers should consider entering discussion and consultation about pregnancy planning, healthy lifestyles before pregnancy, and contraception into the routine care of HIV/AIDS patients in order to maximise the health of people living with HIV and their sexual partners and to protect their future children from the disease, thus preventing further spread of the disease.

\section{Acknowledgments}

This report is part of the qualitative section of a larger study aimed at designing and validating health-related lifestyle tools in people with HIV/AIDS. The researchers would like to thank all the participants in this study as well as the staff members of the Behavioural Disease Counselling Centres of Imam Khomeini Hospital (Tehran) and Rasht, especially Ms. Sheydaee.

\section{Conflict of interest}

The authors declare no potential conflicts of interest with respect to the research, authorship, and/or publication of this article.

\section{References}

1. Auerbach JD. Principles of positive prevention. J Acquir Immune Defic Syndr 2004; 37 Suppl 2: S122-S125.

2. Coetzee D, Hildebrand K, Boulle A, et al. Outcomes after two years of providing antiretroviral treatment in Khayelitsha, South Africa. AIDS 2004; 18: 887-895.

3. Smith DJ, Mbakwem BC. Antiretroviral therapy and reproductive life projects: mitigating the stigma of AIDS in Nigeria. Soc Sci Med 2010; 71: 345-352. 
4. Global HIV \& AIDS statistics - 2018 fact sheet. UNAIDS. Available at: www.unaids.org/en/resources/fact-sheet.

5. Lewis JJ, Ronsmans C, Ezeh A, Gregson S. The population impact of HIV on fertility in sub-Saharan Africa. AIDS 2004; 18: S35-S43.

6. Chen JL, Philips KA, Kanouse DE, Collins RL, Miu A. Fertility desires and intentions of HIV-positive men and women. Fam Plann Perspect 2001; 33: 144-152, 165.

7. Segurado AC, Paiva V. Rights of HIV positive people to sexual and reproductive health: parenthood. Reprod Health Matters 2007; 15 (29 Suppl): 27-45.

8. Sexual and reproductive health needs and preferences of people living with HIV/AIDS in Southern Nations Nationalities and Peoples Region. Addis Ababa University.

9. Hajizadeh, S., et al., Fertility Intentions of HIV Patients who Referred to Behavioral Clinics of Universities of Medical Sciences in Tehran. J Isfahan Medical School 2012; 29: 2427-2436.

10. Gruskin S, Ferguson L, O’Malley J. Ensuring sexual and reproductive health for people living with HIV: an overview of key human rights, policy and health systems issues. Reprod Health Matters 2007; 15 (20 Suppl): 4-26.

11. Beyeza-Kashesya J, Kaharuza F, Mirembe F, Neema S, Ekstrom AM, Kulane A. The dilemma of safe sex and having children: challenges facing HIV sero-discordant couples in Uganda. Afr Health Sci 2009; 9: 2-12.

12. Nedjat S, Moazen B, Rezaei F, et al. Sexual and reproductive health needs of HIV-positive people in Tehran, Iran: a mixed-method descriptive study. Int J Health Policy Manag 2015; 4: 591-598.

13. Abasiubong F, Udoh SB, Idung AU, et al. Attitudes and sexual behaviours of unmarried people with HIV/AIDS living in the Niger Delta region of Nigeria. Ment Health Fam Med 2012; 9: 225-232.

14. King R, Katuntu D, Lifshay J, et al. Processes and outcomes of HIV serostatus disclosure to sexual partners among people living with HIV in Uganda. AIDS Behav 2008; 12: 232-243.

15. Gaede B, Majeke S, Modeste RRM, et al. Social support and health behaviour in women living with HIV in KwaZulu-Natal. SAHARA J 2006; 3: 362-368.

16. Kalichman SC, Ntseane D, Nthomang K, et al. Recent multiple sexual partners and HIV transmission risks among people living with HIV/AIDS in Botswana. Sex Transm Infect 2007; 83: 371-375.

17. Bateganya M, Colfax G, Shafer LA, et al. Antiretroviral therapy and sexual behavior: a comparative study between antiretroviral-naive and-experienced patients at an urban HIV/AIDS care and research center in Kampala, Uganda. AIDS Patient Care STDS 2005; 19: 760-768.

18. Niccolai LM, D’Entremont D, Pritchett EN, Wagner K. Unprotected intercourse among people living with HIV/AIDS: the importance of partnership characteristics. AIDS Care 2006; 18: 801-807.

19. Eisele TP, Mathews C, Chopra M, et al. Changes in risk behavior among HIV-positive patients during their first year of antiretroviral therapy in Cape Town South Africa. AIDS Behav 2009; 13: 1097-1105.

20. Courtenay-Quirk C, Zhang J, Wolitski RJ. Intentional abstinence among homeless and unstably housed persons living with HIV/ AIDS. AIDS Behav 2009; 13: 1119-1128.

21. MacLachlan EW. Factors that influence risk behavior in HIV infected women receiving antiretroviral therapy in Kampala and Masaka, Uganda. 2007.

22. Graneheim UH, Lundman B. Qualitative content analysis in nursing research: concepts, procedures and measures to achieve trustworthiness. Nurse Educ Today 2004; 24: 105-112.

23. Speziale HS, Streubert HJ, Carpenter DR. Qualitative research in nursing: advancing the humanistic imperative. Lippincott Williams \& Wilkins, 2011.

24. Aghasi M, Fallah, F. Iranian youth's attitude towards marriage, spouse's choice and family formation. Women's Research Special Report. Institute of Humanities and Cultural Studies 2016; 6: 1-27 [In Persian].
25. Parvin S, Eslamian A. The lived experience of women living with HIV in social relationships. Woman in Development and Politics 2014; 12: 207-228 [In Persian].

26. Fallahi F, Tavafian S, Yaghmaie F, Hajizadeh E. Consequences of living with HIV/AIDS: a qualitative study. Journal of the Iranian Institute for Health Sciences Research (Payesh) 2013; 12: 243-253 [In Persian].

27. Abachi A, Behravan H. The analysis of stigma impact on quality of life in patients with HIV/AIDS: a phenomenological study. J Qual Res Health Sci 2013; 2: 158-172 [In Persian].

28. Rispel LC, Metcalf CA, Moody K, Cloete A, Caswell G. Sexual relations and childbearing decisions of HIV-discordant couples: an exploratory study in South Africa and Tanzania. Reprod Health Matters 2011; 19: 184-193.

29. Hajizadeh Sh, Nedjat S, Majdzadeh R, et al. High-risk behaviors of HIV positive individuals referred to Behavioral Counselling Centers of Universities of Medical Sciences in Tehran. Journal of School of Public Health and Institute of Public Health Research 2012; 10: 65-76 [In Persian].

30. Johnson P. Risky health behaviors and neurocognitive function among people living with HIV. University of Southern California, 2009.

31. Cleland J, Sinding S. What would Malthus say about AIDS in Africa? Lancet 2005; 366: 1899-1901.

32. Amoran O, Ladi-Akinyemi T. Sexual risk history and condom use among people living with HIV/AIDS in Ogun State, Nigeria. J Sex Med 2012; 9: 997-1004.

33. Dessie Y, Deresa M. Sexual practices of HIV-positive individuals attending antiretroviral treatment (ART) in Addis Ababa public hospitals: findings from in-depth interview. Pan Afr Med J 2012; 13: 80.

34. Adeniyi OV, Ajayi AI, Selanto-Chairman N, et al. Demographic, clinical and behavioural determinants of HIV serostatus non-disclosure to sex partners among HIV-infected pregnant women in the eastern cape, South Africa. PLoS One 2017; 12: e0181730.

35. Esmaelzadeh-Saeieh S, Ebadi A, Mahmoodi Z, et al. Barriers to disclosure of disease in HIV-infected women: a qualitative study. HIV AIDS Rev 2018; 17: 12-17.

36. Cooper D, Moodley J, Zweigenthal V, et al. Fertility intentions and reproductive health care needs of people living with HIV in Cape Town, South Africa: implications for integrating reproductive health and HIV care services. AIDS Behav 2009; 13 Suppl 1: 38-46.

37. Crepaz N, Marks G. Serostatus disclosure, sexual communication and safer sex in HIV-positive men. AIDS Care 2003; 15: 379-387.

38. Gogna ML, Pecheny MM, Ibarlucía I, et al. The reproductive needs and rights of people living with HIV in Argentina: health service users' and providers' perspectives. Soc Sci Med 2009; 69: 813-820.

39. Panozzo L, Battegay M, Friedl A, Vernazza PL; Swiss Cohort Study. High risk behaviour and fertility desires among heterosexual HIV-positive patients with a serodiscordant partner - two challenging issues. Swiss Med Wkly 2003; 133: 124-127.

40. Fallahi H, et al. HIV/AIDS people's perspectives on barriers to condom use: a qualitative research. Payesh Quarterly 2012; 11: 831840 [In Persian].

41. Ngure K, Mugo N, Celum C, et al. A qualitative study of barriers to consistent condom use among HIV-1 serodiscordant couples in Kenya. AIDS Care 2012; 24: 509-516.

42. Cunha CB, De Boni RB, Guimarães MR, et al. Unprotected sex among men who have sex with men living with HIV in Brazil: a cross-sectional study in Rio de Janeiro. BMC Public Health 2014; 14: 379.

43. Halkitis PN, Parsons JT, Wilton L. Barebacking among gay and bisexual men in New York City: Explanations for the emergence of intentional unsafe behavior. Arch Sex Behav 2003; 32: 351-357.

44. Loutfy M, Raboud J, Wong J, et al., High prevalence of unintended pregnancies in HIV-positive women of reproductive age in Ontario, Canada: a retrospective study. HIV Med 2012; 13: 107-117. 
45. Wilcher R, Cates W Jr. Reaching the underserved: family planning for women with HIV. Studies in Family Planning 2010; 41: 125-128.

46. Wanyenze RK, Tumwesigye NM, Kindyomunda R, et al. Uptake of family planning methods and unplanned pregnancies among HIV-infected individuals: a cross-sectional survey among clients at HIV clinics in Uganda. J Int AIDS Soc 2011; 14: 35.

47. Smits AK, Goergen CA, Delaney JA, et al. Contraceptive use and pregnancy decision making among women with HIV. AIDS Patient Care STDS 1999; 13: 739-746.

48. Ezeanolue EE, Wodi AP, Patel R, et al. Sexual behaviors and procreational intentions of adolescents and young adults with perinatally acquired human immunodeficiency virus infection: experience of an urban tertiary center. Journal of Adolescent Health 2006; 38 : 719-725.

49. Loutfy MR, Hart TA, Mohammed SS, et al. Fertility desires and intentions of HIV-positive women of reproductive age in Ontario, Canada: a cross-sectional study. PLoS One 2009; 4: e7925.

50. Oladapo OT, Daniel OJ, Odusoga OL, Ayoola-Sotubo O, et al. Fertility desires and intentions of HIV-positive patients at a suburban specialist center. J Natl Med Assoc 2005; 97: 1672-1681.

51. Grzeszczuk J, Wroblewska A, Firląg-Burkacka E, Kowalska JD. The characteristics of HIV serodiscordant couples consulted at the HIV Out-Patient Clinic in Warsaw. HIV AIDS Rev 2017; 16: 58-60.

52. Glynn JR, Buvé A, Caraël M, et al. Decreased fertility among HIV-1-infected women attending antenatal clinics in three African cities. J Acquir Immune Defic Syndr 2000; 25: 345-352.

53. Carpenter LM, Nakiyingi JS, Ruberantwari A, et al. Estimates of the impact of HIV infection on fertility in a rural Ugandan population cohort. Health Transition Review 1997; 7 (Suppl 2): 113-126.

54. Dabash R. Sexual and reproductive health needs of women and adolescent girls living with HIV. Research report on qualitative findings from Brazil Ethiopia and the Ukraine. 2006.

55. Kirshenbaum SB, Hirky AE, Correale J, et al. "Throwing the dice": pregnancy decision-making among HIV-positive women in four U.S. cities. Perspect Sex Reproduct Health 2004; 36: 106-113.

56. Behboodi-Moghadam Z, Esmaelzadeh S, Ebadi A, Nikbakht Nasrabadi A. Development and psychometric evaluation of a reproductive health assessment scale for HIV-positive women. Shiraz E Medical Journal 2016; 17.

57. Loutfy MR, Blitz S, Zhang Y. Self-reported preconception care of HIV-positive women of reproductive potential: a retrospective study. Journal of the International Association of Providers of AIDS Care (JIAPAC) 2014; 13: 424-433.

58. Wagner GJ, Ryan GW. Relationship between routinization of daily behaviors and medication adherence in HIV-positive drug users. AIDS Patient Care STDS 2004; 18: 385-393. 